\title{
Fanconi's Anemia and Other Hereditary Bone Marrow Failure Syndromes
}

\author{
Cristina Díaz de Heredia, Marc Bierings, \\ Jean-Hugues Dalle, Francesca Fioredda, \\ and Brigitte Strahm
}

\subsection{Introduction}

Inherited bone marrow failure syndromes (IBMFS) are a heterogeneous group of rare blood disorders due to hematopoiesis impairment, with different clinical presentations and pathogenic mechanisms. Some patients present congenital malformations, may progress through clonal evolution (MDS and acute leukemia), and are at risk of solid tumors at early ages. The number of involved genes rises annually; comprehensive

C. Díaz de Heredia $(\bowtie)$

Department of Pediatric Hematology and Oncology and HSCT, Hospital Universitari Vall d'Hebron, Barcelona, Spain

e-mail: crdiaz@vhebron.net

M. Bierings

Pediatric Hematology and HSCT Division,

Wilhelmina Kinderziekenhuis, Utrecht, Netherlands

J.-H. Dalle

HSCT Programme, Hemato Immunology

Department, Hôpital Robert Debré Université Paris

7 - Denis Diderot, Paris, France

F. Fioredda

Hematology Unit, Istituto Giannina Gaslini,

Genoa, Italy

B. Strahm

Department of Pediatrics and Adolescent Medicine Division of Pediatric Hematology and Oncology, Medical Center Faculty of Medicine, University of Freiburg, Freiburg im Breisgau, Germany next-generation sequencing analyses improve diagnostic accuracy. HSCT is an option for these congenital disorders. However, it should be well understood that it will only improve the hematopoietic defect and not cure the congenital malformations or lower the risk of solid tumors. Moreover, the HSCT procedure per se may increase this risk. Consequently, the decision to transplant a patient should be taken by a multidisciplinary team. HSCT must be performed at specialized centers owing to patient susceptibilities to toxicity and the need for specific management during and after the procedure. The general recommendations for management of IBMFS are included in the key points at the end of the chapter.

\subsection{Fanconi's Anemia}

\subsubsection{Pathogenesis and Principal Clinical Features}

Fanconi's anemia (FA) is the most common IBMFS with an estimated incidence of 1/200,000. FA is a disorder of DNA damage repair, leading to increased chromosomal breakage in diagnostic assays. Twenty underlying genes have been identified. The presentation is variable with somatic abnormalities in $70 \%$ of patients, marrow failure, and a highly increased risk of malignancies (MDS, leukemia, head and neck cancer, gynecological cancers) at an early age. Patients can be 
identified at adult age, e.g., in cases of (familial) pancytopenia, myelodysplasia, or unexpected severe toxicity of treatment. FA patients are highly susceptible to chemotherapy and irradiation-induced damage such as mucositis.

\subsubsection{Indications of HSCT}

Indications for transplant include marrow failure (transfusion dependency or severe neutropenia) and myelodysplasia/leukemia. Since transplantation implies exposure to chemo/radiotherapy and since the outcome is dependent on age at transplant, the decision to proceed to transplant should be individualized and discussed with experts in the field.

\subsubsection{Specific Considerations for Conditioning Regimen}

Conditioning regimens should be adapted for FA patients, with reduced doses of many cytotoxic drugs and irradiation. Current conditioning regimens generally contain FLU (cumulative dose $150 \mathrm{mg} / \mathrm{m}^{2}$ ), in combination with reduced doses of CY (up to $50 \mathrm{mg} / \mathrm{kg}$ cumulative) and/or lowdose TBI (100-300 cGy) in the case of unrelated donors. For adults no clear recommendations can be given at this point.

\subsubsection{Results}

Current results of transplant for marrow failure in children with FA show survival rates depending on donor type ranging from $50 \%$ to more than $90 \%$. Factors influencing outcome include age at transplant, sibling donor availability, and the use of FLU in the conditioning regimen. A EBMT study of the period 2000-2009 reported 78\% and $65 \%$ OS at 5-year post transplant for MSD and MUD, respectively (Fig. 78.1).

Clonal disease and adult age at transplant remain a challenge. Both TRM and relapse of malignant disease contribute to these generally poor results.

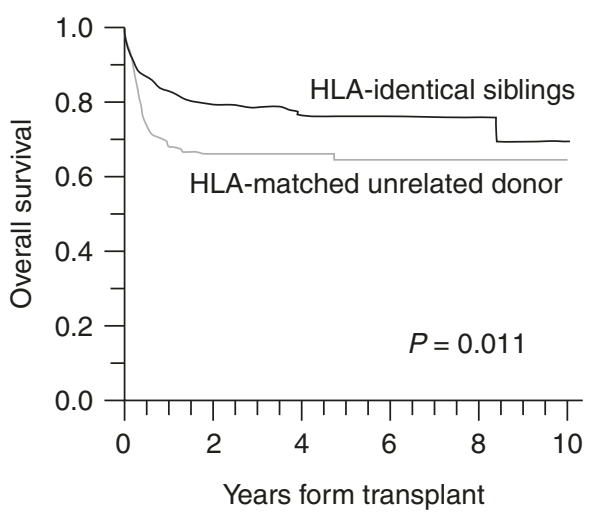

No. at risk:

HLA-id. sib $211 \quad 126 \quad 76 \quad 41 \quad 14 \quad 3$

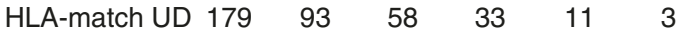

Fig. 78.1 OS for Fanconi's anemia according to the type of donor: transplant period 2000-2009. The EBMT experience. Peffault de Latour R. Blood 2013; 122: 4279-86

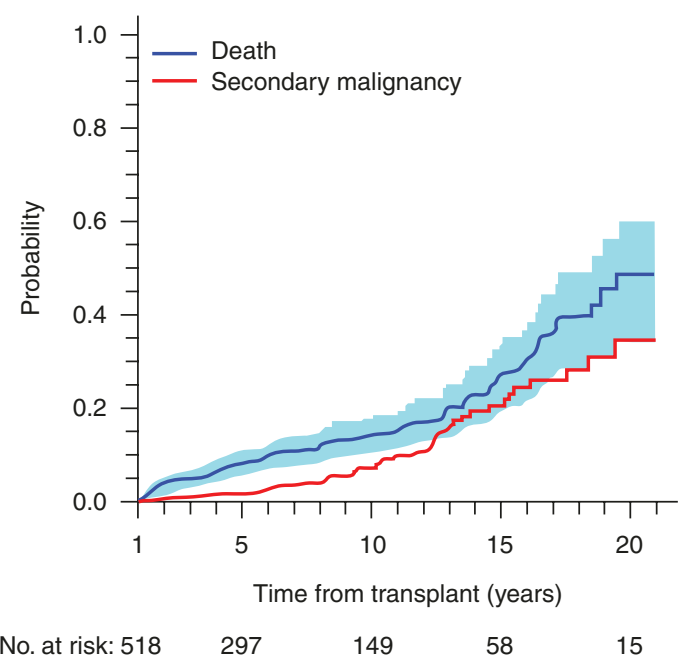

Fig. 78.2 Fanconi's anemia: probability of death and secondary malignancies post transplant. The EBMT experience. Peffault de Latour R. Blood 2013; 122: 4279-86

\subsubsection{Recommendations for Long- Term Follow-Up}

After transplant, the risk of secondary malignancies is high (Fig. 78.2). Patients should be carefully monitored for head-neck malignancies (regular ear, nose, and throat specialist checks for early signs of malignant transformation, and women undergo gynecological checkups and 
screening for breast cancer with ultrasound and MRI) and other manifestations of FA (e.g., endocrinopathies such as thyroid dysfunction, diabetes, growth problems, and early menopause). As more FA patients survive into adulthood, specialist multidisciplinary teams taking care of these complex patients are needed.

\subsection{Dyskeratosis Congenita}

\subsubsection{Pathogenesis and Principal Clinical Features}

Dyskeratosis congenita (DC) is a multisystemic disorder characterized by the nail dystrophy, skin pigment alteration and oral leukoplakia triad frequently associated with bone marrow failure and organ involvement (pulmonary fibrosis, liver, neurological and gastrointestinal abnormalities, ocular impairment and cancer predisposition). The causative mechanism of the disease is abnormal telomere shortening due to a defect in one of the genes encoding for the telomerase-shelterin complex. Bone marrow failure is the main cause of death, although pulmonary fibrosis, liver cirrhosis, and cancer significantly contribute to morbidity and mortality. Androgens have shown some effect on hematopoiesis and lung function.

\subsubsection{Indications for Transplant}

HSCT is the only curative option for bone marrow failure in DC. Organ dysfunction is not corrected by HSCT and limits its indication by negatively affecting outcome. HSCT is not indicated as a preemptive measure but is recommended in cases of progressive marrow failure without significant organ dysfunction.

\subsubsection{Specific Considerations for Donor Selection and Conditioning Regimen}

MSD are the donors of choice; MUD and mismatched related donors are associated with inferior outcomes. Given tissue "fragility," a reduced intensity combination containing fludarabine would be preferable to myeloablative regimen. A thorough evaluation of organ status is recommended prior to transplant.

\subsubsection{Results}

Five- and 10-year survival is $57 \%$ and $23 \%$, respectively. Age $>20$ years at HSCT, HSCT before 2000 and alternative donor transplant were poor prognostic markers. Patients transplanted after 2000 had improved early survival to $70 \%$ at 5-year post transplant.

\subsubsection{Specific Recommendations for Long-Term Follow-Up}

Since HSCT may increase the risk of secondary malignancies in these patients, long-term followup is mandatory.

\subsection{Severe Congenital Neutropenia and Shwachman-Diamond Syndrome}

\subsubsection{Pathogenesis and Principal Clinical Features}

The term "severe congenital neutropenia" (SCN) covers a group of inherited disorders characterized by a persistent absolute neutrophil count (ANC) below $0.5 \times 10^{9} / \mathrm{L}$ and early onset of severe infections. To date, 24 distinct genes have been associated with SCN which may manifest as an isolated disorder or associated with various extra-hematologic features.

The most common form (60\%) of genetic neutropenia is due to mutations in the ELANE gene. Shwachman-Diamond syndrome (SDS) caused by a mutation of $S D S B$ gene is the most common form of neutropenia associated with extra-hematologic features (exocrine pancreas deficiency, metaphyseal dysplasia, mental retardation, cardiomyopathy, and immune dysfunction). 
The underlying pathogenic mechanism of most genetic SCN is accelerated apoptosis of promyelocytes causing blockage of neutrophil maturation. In SDS, the defect in the SBDS protein causes abnormal ribosomal assembly and inadequate maintenance of the stromal microenvironment.

The SCN clinical phenotype consists of predisposition to severe infections. The use of G-CSF improved the prognosis of the disease which had been lethal in almost $50 \%$ of cases. The aim of treatment is to maintain protective neutrophil values (between 1.0 and $\left.5.0 \times 10^{9} / \mathrm{L}\right)$ that are usually achieved with G-CSF doses of $3-5 \mu \mathrm{g} / \mathrm{kg} /$ day. Patients requiring G-CSF between 10 and $15 \mu \mathrm{g} / \mathrm{kg} /$ day are defined as "poor responders," whereas those requiring $>20 \mu \mathrm{g} / \mathrm{kg} /$ day are considered "non-responders."

Another feature of SCN is its tendency to transform into MDS/AL. The overall cumulative incidence of MDS/AL is $10.8 \%$ and $22 \%$ after 15-20 years of G-CSF treatment according to the French and International Severe Chronic Neutropenia Registries, respectively. In SDS the cumulative incidence is between $18 \%$ and $36 \%$ at 20-30 years.

\subsubsection{Indications for Transplant}

The definitive cure of the hematologic defect is HSCT. Given the non-negligible mortality rate, indications are limited to patients with MDS/AL and absent or poor response to G-CSF. For SDS the indications for transplant are worsening cytopenias with increased transfusion dependence and transformation into MDS/AL.

\subsubsection{Specific Considerations for Conditioning Regimen}

A MAC regimen is considered appropriate in $\mathrm{SCN}$, while a RIC is more indicated in SDS owing to possible secondary organ dysfunction (e.g., heart disease).

\subsubsection{Results}

OS has been assessed at $82 \%$ with TRM of $17 \%$ in the largest cohort (136 patients) described. Better results have been obtained in patients under 10 years of age, in those transplanted after 2000 and in cases of MSD transplants.

\subsection{Diamond-Blackfan Anemia}

\subsubsection{Pathogenesis and Principal Clinical Features}

Diamond-Blackfan anemia (DBA) is a rare IBMFS caused by heterozygous mutations in ribosomal genes. No genetic aberration is identified in approximately $30 \%$ of patients. Patients usually present with transfusion-dependent macrocytic anemia at birth or in early infancy. Mild neutropenia and progressive thrombocytopenia have been observed in the course of the disease. Despite various possible physical abnormalities (short stature, abnormal thumbs, cleft palate, heart defects, urogenital malformations), the non-hematologic phenotype is usually rather subtle in around $50 \%$ of patients. Patients with DBA are at increased risk of developing hematologic (AML/MDS) and non-hematologic malignancies (osteosarcoma, colon cancer).

After the first year of life, at least two trials of steroid therapy are recommended; around $60 \%$ of the patients are responders. Patients $<12$ months of age or those who are steroid non-responders are treated with red blood cell (RBC) transfusions. Iron chelation is essential to prevent organ damage from iron overload. About 20\% of patients become transfusion independent with no further treatment (spontaneous remission).

\subsubsection{Indications for Transplant}

HSCT is the only cure for hematologic manifestations. Indications are non-response to steroids, steroid dependency at a dose $\geq 0.3 \mathrm{mg} / \mathrm{kg} /$ day, transfusion dependency, alloimmunization to 
RBC, progressive pancytopenia, or MDS/ AML. Published data indicate that HSCT should be performed before the age of 10 years; however, an earlier time point might be preferable to avoid iron overload. Indications must be evaluated taking into account the alternative approach with RBC transfusions combined with rigorous iron chelation.

\subsubsection{Specific Considerations for Donor Selection and Conditioning Regimen}

HSCT from a MSD including cord blood has resulted in OS $>80 \%$ and is recommended for all indications. Sibling donors should be carefully assessed to rule out silent carrier status. Recent reports described improved outcome of MUD HSCT with OS ranging from 70 to $85 \%$ (Strahm, EBMT abstract 2018). By contrast, data supporting HSCT from mismatched donors as standard procedure are insufficient. The majority of transplants reported were performed with myeloablative conditioning. Based on available data, a standard regimen including FLU and $\mathrm{BU}$ or TREO is recommended.

\subsubsection{Specific Recommendations for Long-Term Follow-Up}

Long-term care for patients being transplanted for DBA should focus on the management of iron overload. Depending on its extent, phlebotomies and/or iron chelation therapy might be indicated. Furthermore, patients and physicians should be aware of the increased risk of malignancies (especially osteosarcoma, colon cancer).

\subsection{Congenital Amegakaryocytic Thrombocytopenia}

\subsubsection{Pathogenesis and Principal Clinical Features}

Congenital amegakaryocytic thrombocytopenia (CAMT) is a rare IBMFS caused by mutations in the gene coding for the thrombopoietin receptor MPL. Patients usually present with thrombocytopenia at birth or within the first year of life. Most patients develop hypocellular bone marrow and progress to pancytopenia early in the course of disease. Clonal evolution with acquired chromosomal aberrations and the development of myelodysplastic syndromes are very rare events. Characteristic non-hematologic manifestations of the disease have not been described.

\subsubsection{Indications for Transplant}

HSCT is the only curative treatment and should be offered to all patients with transfusiondependent thrombocytopenia, pancytopenia, or clonal evolution.

\subsubsection{Specific Considerations for Donor Selection and Conditioning Regimen}

HSCT from a MSD is the preferred option, and successful transplants from heterozygous-related donors have been reported. HSCT from MUD $(\geq$ $9 / 10)$ is an acceptable alternative. Successful HSCT from mismatched family donors or mismatched unrelated cord blood donors have been reported. However, these should preferentially be performed in clinical trials.

In view of a considerable graft failure rate, a MAC with FLU in combination with TREO or BU is preferred. However, there have been reports of successful engraftment after a RIC, and this might be considered in cases with severely hypocellular bone marrow in the absence of clonal aberrations and alloimmunization to platelet transfusions.

\subsubsection{Results}

Five-year overall survival was $77 \%$ with TRM of $12.6 \%$ in a retrospective EBMT study. However, this series included HSCT performed over a period of 26 years with a variety of donors, regimens, and stem cell sources, with no difference in outcome. 


\begin{tabular}{|c|c|}
\hline nts & \\
\hline Patient & $\begin{array}{l}\text { - Evaluate carefully hematologic and } \\
\text { extra-hematologic manifestations of } \\
\text { the disease prior to transplant }\end{array}$ \\
\hline Donor & $\begin{array}{l}\text { - The best donor is MSD; however, it is } \\
\text { mandatory to test the genetic defect in } \\
\text { the donor since some IBMFS may } \\
\text { present different clinical and } \\
\text { hematologic expression in members } \\
\text { of the same family } \\
\text { - Consider MUD in case of no } \\
\text { appropriate MSD } \\
\text { - Mismatched related and UD and } \\
\text { unrelated CB only in experienced } \\
\text { centers and preferentially in clinical } \\
\text { trials }\end{array}$ \\
\hline $\begin{array}{l}\text { Source of } \\
\text { stem cells }\end{array}$ & $\begin{array}{l}\text { BM is the best source of stem cells } \\
\text { Matched related CB is a good option } \\
\text { PB is associated with higher risk of } \\
\text { cGVHD and should be avoided }\end{array}$ \\
\hline Cell dose & $\begin{array}{l}\text { It is important for graft failure } \\
\text { prevention: } \\
\mathrm{NC}>3 \times 10^{8} / \mathrm{kg} \text { recipient bw for } \mathrm{BM} \\
\mathrm{NC}>3 \times 10^{7} / \mathrm{kg} \text { recipient bw for } \\
\text { related } \mathrm{CB} \\
\mathrm{NC}>4 \times 10^{7} / \mathrm{kg} \text { recipient bw for } \\
\text { unrelated } \mathrm{CB}\end{array}$ \\
\hline $\begin{array}{l}\text { Conditioning } \\
\text { regimen }\end{array}$ & $\begin{array}{l}\text { MAC or RIC depending on the type of } \\
\text { IBMF } \\
\text { Irradiation should be avoided owing to } \\
\text { the known risk of cancer } \\
\text { Patients with Fanconi's anemia and } \\
\text { dyskeratosis congenita must receive a } \\
\text { RIC }\end{array}$ \\
\hline $\begin{array}{l}\text { GVHD } \\
\text { prophylaxis }\end{array}$ & $\begin{array}{l}\text { GVHD must be avoided } \\
\text { Include two immunosuppressive drugs } \\
\text { Serotherapy for UD transplants }\end{array}$ \\
\hline $\begin{array}{l}\text { Long-term } \\
\text { follow-up }\end{array}$ & $\begin{array}{l}\text { - It is mandatory owing to high risk of } \\
\text { secondary malignancies, extra- } \\
\text { hematologic manifestations and iron } \\
\text { overload } \\
\text { - Patients should be followed-up by a } \\
\text { multidisciplinary team }\end{array}$ \\
\hline
\end{tabular}

\section{Recommended References}

Ayas M, Saber W, Davies SM, et al. Allogeneic hematopoietic stem cell transplantation for Fanconi anemia in patients with pre-transplantation cytogenetic abnormalities, myelodysplastic syndrome or acute leukemia. J Clin Oncol. 2013;31:1669-76.

Ballmaier M, Germeshausen M. Congenital amegakaryocytic thrombocytopenia: clinical presentation, diagnosis, and treatment. Semin Thromb Hemost. 2011;37:673-81.
Barbaro P, Vedi A. Survival after hematopoietic stem cell transplant in patients with dyskeratosis congenita: a systematic review of the literature. Biol Blood Marrow Transplant. 2016;22:1152-8.

Benajiba L, Salvado C, Dalle JH, et al. HLA-matched related donor HSCT in Fanconi anemia patients conditioned with cyclophosphamide and fludarabine. Blood. 2015;125:417-8.

Bizzetto R, Bonfim C, Rocha V, et al. Outcomes after related and unrelated umbilical cord blood transplantation for hereditary bone marrow failure syndromes other than Fanconi anemia. Haematologica. 2011;96:134-41.

Dalle JH, Fahd M, et al. Allogeneic stem cell transplantation in amegacaryocytosis: results of a retrospective study in EBMT centers. Biol Blood Marrow Transplant. 2014;20:S81-2.

Donadieu J, Beaupain B, Fenneteau O, et al. Congenital neutropenia in the era of genomics: classification, diagnosis, and natural history. Br J Haematol. 2017;79:557-74.

Dufour C. How I manage patients with Fanconi anaemia. Br J Haemat. 2017;178:32-47.

Fagioli F, Quarello P, Zecca M, et al. Haematopoietic stem cell transplantation for diamond Blackfan anaemia: a report from the Italian association of Paediatric Haematology and oncology registry. Br J Haematol. 2014;165:673-81.

Fioredda F, Iacobelli S, van Biezen A, et al. Severe aplastic anemia the inborn error and the pediatric disease working parties of the European Society for Blood and Bone Marrow Transplantation (EBMT) and stem cell transplant for Immunodeficiencies in Europe (SCETIDE). Stem cell transplantation in severe congenital neutropenia: an analysis from the European Society for Blood and Marrow Transplantation. Blood. 2015;126:1885-92.

Frangoul H, Keates-Baleeiro J, Calder C, et al. Unrelated bone marrow transplant for congenital amegakaryocytic thrombocytopenia: report of two cases and review of the literature. Pediatr Transplant. 2010;14:E42-5.

Knight S, Vulliamy T, Copplestone A, et al. Dyskeratosis congenita (DC) registry: identification of new features of DC. Br J Haematol. 1998;103:990-6.

Mahadeo KM, Tewari P, Parikh SH, et al. Durable engraftment and correction of hematological abnormalities in children with congenital amegakaryocytic thrombocytopenia following myeloablative umbilical cord blood transplantation. Pediatr Transplant. 2015;19:753-7.

Meerpohl JJ, Kartal BME, et al. Stem cell transplantation in diamond-Blackfan Anaemia: a retrospective analysis. Bone Marrow Transplant. 2009;43:S76.

Mugishima H, Ohga S, Ohara A, et al. Hematopoietic stem cell transplantation for diamond-Blackfan anemia: a report from the aplastic anemia Committee of the Japanese Society of pediatric hematology. Pediatr Transplant. 2007;11:601-7. 
Muraoka K, Ischii E. IharaK et al. successful bone marrow transplantation in a patient with c-mpl-mutated congenital amegakaryocytic thrombocytopenia from a carrier donor. Pediatr Transplant. 2005;9:101-3.

Peffault de Latour R, Peters C, Gibson B, et al. On behalf of the pediatric working Party of the European Group for blood and marrow transplantation and the severe aplastic anemia working Party of the European Group for blood and marrow transplantation. Recommendations on hematopoietic stem cell transplantation for inherited bone marrow failure syndromes. Bone Marrow Transplant. 2015;50:1168-72.

Peffault de Latour R, Porcher R, Dalle JH, et al. Allogeneic hematopoietic stem cell transplantation in Fanconi anemia: the European Group for Blood and Marrow Transplantation experience. Blood. 2013;122:4279-86.

Rosenberg PS, Zeidler C, Bolyard AA, et al. Stable longterm risk of leukaemia in patients with severe congenital neutropenia maintained on G-CSF therapy. Br J Haematol. 2010;150:196-9.

Savage SA, Dufour C. Classical inherited bone marrow failure syndromes with high risk for myelodysplastic syndrome and acute myelogenous leukemia. Semin Hematol. 2017;54:105-14.

Vlachos A, Muir E. How I treat diamond-Blackfan anemia. Blood. 2010;116:3715-23.

Woods G, Bajwa RP, Rose MJ, et al. Reduced intensity transplantation for congenital amegakaryocytic thrombocytopenia: report of a case and review of the literature. Pediatr Transplant. 2014;18:E31-4.

Open Access This chapter is licensed under the terms of the Creative Commons Attribution 4.0 International License (http://creativecommons.org/licenses/by/4.0/), which permits use, sharing, adaptation, distribution and reproduction in any medium or format, as long as you give appropriate credit to the original author(s) and the source, provide a link to the Creative Commons license and indicate if changes were made.

The images or other third party material in this chapter are included in the chapter's Creative Commons license, unless indicated otherwise in a credit line to the material. If material is not included in the chapter's Creative Commons license and your intended use is not permitted by statutory regulation or exceeds the permitted use, you will need to obtain permission directly from the copyright holder. 